\title{
Violent children and the media
}

\author{
Susan Bailey
}

Few subjects attract the attention of the public and the media more than violent acts committed by children and adolescents. All too frequently. politicians, policy-makers, practitioners, the public and media become caught up in destructive cycles of blame, engendering within society itself a sense of helplessness and powerlessness for and about violent young people.

From the earliest days of television, parents and social critics have expressed concern about the possible negative effects of the media on children. Snyder, in an overview of 'movies and the adolescent', emphasises that the adolescent of today, perhaps as much as any generation, is in search of identity (1992). Films may provide either acceptable or inappropriate role models that adolescents utilise as examples for social learning.

In the field of violent offending in juveniles, review of the mass of available research reveals three major and interacting risk areas: child centred, family centred and contextual.

Contextual factors, as well as peer group interaction, crime opportunity, drug and alcohol misuse, and unemployment with associated poverty, include the fast forward world of video, television and film. Within the cycles of abuse and violence literature are studies that address the impact of witnessing violence on children's later behaviour. These studies fall into three basic types: large-scale surveys that correlate self-reports of exposure to violence with adult approval of violence or marital violence; studies of the children of battered women; and studies of television violence and aggressive behaviour. It is important to note that the television and violence literature is characterised by a variety of designs, viewing stimuli, circumstances and measures of aggression.

Whether the aggression and violent behaviour measured in the television violence studies can be generalised beyond the laboratory to real life behaviour or delinquency or criminality has been seriously questioned. However, in prospective longitudinal studies the amount of violent television watched at age 9 was a good predictor of juvenile delinquency offences related to aggression at age 19. Increased levels of aggression after viewing television violence, emotional insensitivity and a distorted perception of reality bear a marked resemblance to findings from research on delinquency and in particular violent offenders. The extent of a young person's reported television viewing may not in and of itself be the best predictor of violent criminal acts; rather it is the interlacing interaction of large amounts of television and exposure to earlier and/or ongoing parental abuse that is related to violent crime.

Humans are in constant interaction with their environment, reacting to information they take in and adjusting to demands placed upon them. Within a vulnerable group of young people (that may include up to $10 \%$ of the population of young people), unaddressed, traumatic and early damaging experiences set in motion a certain thinking pattern. A structure of thinking begins to emerge that motivates and sustains deviant behaviour through developmental and interpersonal failure and through the alliance of distorted perceptions. Of particular importance is the activation of aggression and its link to sexual expression. Ressler \& Burgess (1988) reviewed the childhood sexual experiences of 36 adolescents and adults who latter committed sexual homicide. This study revealed the strong reliance offenders placed on visual sexual stimuli; pornography ranked highest $(81 \%)$ and reemerged in their subsequent act of organised or disorganised killing.

In a recent study of child and adolescent murderers, we found similarities to classic studies in the US. Past history of violence was coupled with neuropsychiatric vulnerabilities, parental brutality, mental illness within the parent group, and a history of the youngster being 'out of control' within home, community and school, in the months prior to the offence. Motivating factors were multiple and overlapping.

Causal factors were 'out of control' behaviour, alcohol, drugs, mental illness, and in 25\% of cases repeated viewing of violent and pornographic videos, especially in the weeks of increasing social isolation prior to the offence. Within this group were youngsters who had adopted reversed sleep patterns, viewing videos in the early hours, returning to particular parts of a film and reliving these over and over again. The technology of visual imaging, in particular the piping of such images directly into family 
homes, continues to advance too quickly for us to take stock and react safely.

A recent study of child and adolescent sex offenders has revealed high psychiatric morbidity in the families of the offenders, psychiatric morbidity in the young people themselves, and a high incidence of offenders being victims themselves. They started to offend at an early age, and have been responsible for many offences - which results in many victims. In individual cases, particularly those where most aggression has been shown in the sexual act against very vulnerable victims, the adolescent in a state of anger and rage has incorporated into his/her fantasy, elements of sex and aggression taken from violent visual imaging. Young sex offenders offending in a 'family, baby-sitting context' give a history of easy access to violent and pornographic videos, sometimes seen not only with peers but in the presence of their young victims. This provides a potent source of immediate arousal for the subsequent act.

In vulnerable children and adolescents, in vulnerable families, it is likely that censorship will not take place. Beyond the immediate content of violent and pornographic videos is the all too often spoken and unspoken message that violence and sexual assault are acceptable and related to individual success and satisfaction.

Viewing of such videos for adolescents who currently have no prospect of 'success' in their own lives, no sense of future vocation or constructive avocation, linked with the potential for them to view such material for hours on end, will contribute to the nature and content of subsequent offences.

The media, in particular television and film, do monitor their own violent and sexual imaging. While not suggesting that society interfere with the freedom of art forms or the right of any of us to receive honest visual communication about current events, this should be tempered with the need to protect the vulnerable' child and adolescent and in doing so protect their future victims.

There is pressing need for a specific study to look at the evolution of violent and sexual fantasy in 'normal' populations of young people and the evolution of sadistic fantasy in a vulnerable group that are at the margins of society, a margin that is currently widening.

No one influence accounts for, or causes, aggression resulting in violent behaviour. The full range of influences is best conceptualised in terms of a risk factor model in which there are multiple influences that contribute to some outcome: in this case the overall level and type of violence in society. Multiple influences combine to increase the likelihood of violent behaviour in young people. Many influences cast aside as small might be argued as actually quite strong and increase the urgency for attention and intervention. There is no better example than the current centre-stage debate about violence and the media.

Efforts to quell pervasive and frequent violence in the media are countered with another set of arguments noting the benefit of television (education, bringing arts to the masses) and the responsibilities of others (especially parents) in policing what children and vulnerable young people view. Yet one set of arguments does not gainsay the others.

The task of reducing violence in childhood and adolescence will not be safely addressed by just labelling and classifying different films, videos and television programmes, based on their level of violence. The task of reducing violence at all other levels (e.g. partner abuse media to which adults are exposed) is likely to have a broader impact. However, this discussion inevitably encroaches on to the territory of what is permitted, or for many even desired, in a free society. The view of the clinician should be rightly heard but this now should be expressed objectively and dispassionately else we risk becoming part of a debate that becomes a form of entertainment in its own right. This only serves to cement the opinion of the 'players' and places those for whom we are genuinely concerned in greater jeopardy.

\section{References}

BAILEY, S. (1996) Adolescents who murder. Journal of Adolescence, 19, 19-39.

Dolan, M., Holloway, J., Balley, S., et al (1996) The psychosocial characteristics of juvenile sexual offenders referred to an adolescent forensic service in the UK. Medicine, Science and the Law, 36. 343-352.

HEATH, L., KNILTSCHNITT, C. \& WARD, D. (1986) Television and Violent Criminal Behaviour: Beyond the Bobo Doll. Violence and Victims.

RESSLER, R. \& BURGESS, A. (1988) Sexual Homicide. Patterns and Motwes. New York: Lexington.

Strasburger, V. C. (1995) Adolescents with the Media. Medical and Psychological Imapct. Sage Publications.

SNYDER, S. (1992) Movies and the Adolescent. An Overvlew. Adolescent Psychiatry.

Susan Bailey, Consultant Adolescent Forensic Psychiatrist, Mental Health Services, Bury New Road, Prestwich, Manchester M25 3BL 